\title{
EVALUATION OF THE LANDSLIDE POTENTIAL IN CAPULIN CANYON FOLLOWING THE DOME FIRE, BANDELIER NATIONAL MONUMENT, NEW MEXICO
}

\author{
By Susan H. Cannon \\ William L. Ellis \\ Jonathan W. Godt
}

\section{Open-File Report 98-42}

This report is preliminary and has not been reviewed for conformity with U.S. Geological Survey editorial standards and nomenclature. Any use of trade, product, or firm names is for descriptive purposes only and does not imply endorsement by the U.S. Government. 


\section{Contents}

Abstract 1

Introduction $\mathbf{2}$

Landslide Descriptions 2

Boundary Peak Landslide 4

Base Camp Landslide 5

Present Stability of Landslide Deposits 6

Global positioning system survey 6

Soil Moisture Monitoring 7

Instrumentation 7

Soil-moisture sensor calibration 8

Instrument locations and installations 9

Results 13

Burned site response 13

Unburned site response 18

Discussion 18

Summary and Conclusions 19

References 21 


\title{
EVALUATION OF THE LANDSLIDE POTENTIAL IN CAPULIN CANYON \\ FOLLOWING THE DOME FIRE, BANDELIER NATIONAI MONUMENT, NEW MEXICO
}

\author{
By Susan H. Cannon, William L. Ellis, and Jonathan W. Godt
}

\begin{abstract}
The Dome fire burned 6684 ha in Bandelier National Monument and the adjacent Santa Fe National Forest in New Mexico. To assess the present stability of the Boundary Peak and Base Camp landslides in Capulin Canyon, and to evaluate the potential for a change in stability due to the removal of vegetation during the fire, a program of mapping and soil-moisture monitoring was undertaken. The Boundary Peak landslide covers an area of approximately $2.9 \mathrm{~km}^{2}$, and appears to be approximately 150 meters thick, while the Base Camp landslide covers approximately $0.2 \mathrm{~km}^{2}$. The thickness of the Base Camp landslide deposits is not known. The Boundary Peak landslide deposits experienced two areas of high burn intensity which cover a total area of approximately $0.15 \mathrm{~km}^{2}$. The remainder of the deposits were mapped as moderate or low burn intensities. The Base Camp deposits show one area of low burn intensity which covers an area of $0.03 \mathrm{~km}^{2}$.

Neither the Boundary Peak and Base Camp landslide deposits exhibit evidence of recent movement or instability. Both landslide deposits are mantled by the 50,000 to 60,000 yearold El Cajete pumice; deposition of the pumice appears to postdate the last movement of the landslides. The entire landslide topography is muted and subdued. No cracks, fissures or shear zones were observed, and only a few tilted trees, too few and far between to indicate instability of the deposits, were observed. The present-day interaction of Capulin Creek and the landslide toes appears to be negligible, and no danger of destabilization of the deposits by undercutting appears to exist at this time.
\end{abstract}

The likelihood of reactivation of the Base Camp landslide deposits due to increased infiltration in areas burned by the Dome fire appears to be negligible due to the small area and low intensity of the fire on the deposits.

Qualitative evaluation of soil-moisture data from the Boundary Peak landslide deposits indicates that (1) over time, and with continued rainfall, moisture infiltrates to greater depths at the burned site than at the unburned site, and (2) the soil at the burned site stays relatively moist throughout the summer monsoon season, while the unburned site dries out rapidly with the onset of warm temperatures. These differences may be due to the lack of vegetationinduced transpiration at the burned sites. Further evaluation is necessary to determine if the increased infiltration could potentially destabilize the landslide deposits. 


\section{INTRODUCTION}

The Dome fire of May, 1996, burned 6684 ha in Bandelier National Monument and the adjacent Santa Fe National Forest in New Mexico. The report of the Burned Area Emergency Rehabilitation (BAER) team that evaluated conditions at the Monument immediately after the fire identified two

Quaternary-age landslide deposits in Capulin Canyon as potentially unstable as a result of the fire, and recommended further evaluation. The larger of the two landslide deposits in Capulin Canyon is located on the north flank of Boundary Peak, while the considerably smaller deposit occurs just southwest of the Ranger Base Camp (fig. 1).

A potential consequence of the reactivation of either of these two landslide deposits is the creation of unstable ground that would pose a navigational hazard for people recreating in the canyon. The integrity of archeological sites on the deposits would be threatened should movement continue for any extended period of time. A possibility, albeit remote, also exists for the landslide deposits to move into Capulin Canyon and dam Capulin Creek. Should this occur, catastrophic failure of the dammed material and the resultant flooding could potentially result in destruction of downstream archeological sites, as well as the loss of human life.

To assess the current stability of these deposits and evaluate the potential for a change in stability due to the removal of vegetation, a two-phase study was initiated. The first phase involved both field and aerial-photographic mapping of the extent of the landslide deposits, paying particular attention to features that could indicate potential instability such as tilting trees and cracks or fissures. Color infra-red aerial photographs taken on May 5, 1996, at 1:8000-scale were used for the mapping. The potential for destabilization of the landslides due to channel incision at the base of the deposits was also assessed by examining conditions at the toe of the landslide deposits in Capulin Canyon. Lastly, an array of survey monuments were established for a GPS-based movement-detection system.
The second phase of the evaluation addresses the issue of a potential change in stability of the landslide mass due to the removal of vegetation by the fire by comparing soil-moisture characteristics and infiltration responses to rainfall and snowmelt events at burned and unburned sites. Two soil-moisture and rainfall monitoring sites were established, one at a burned site on the landslide deposits, and the other on similar unburned terrain. At each site, a series of soil-moisture sensors are used to document the infiltration of rainfall into the soil during summer thunderstorm events. A comparison of soil-moisture data collected through one partial and one complete summer monsoon season at the burned and unburned sites, relative to rainfall accumulations, indicate varying infiltration characteristics of the two sites, some of which might be attributed to live tree transpiration rates.

This report consists of the following elements:

- Descriptions of the landslides, the observations made, and the conclusions drawn regarding their morphology, mode of fail ure, and present stability.

- Description of the GPS survey methods and array.

- Description of the soil-moisture monitoring experiment and evaluation of data collected through one partial and one complete summer monsoon season.

- Conclusions regarding the likelihood of major landslide activity in the canyon.

\section{LANDSLIDE DESCRIPTIONS}

The larger of the two landslides is located on the north flank of Boundary Peak and is referred to as the Boundary Peak landslide in this report (fig. 1). The other, considerably smaller, landslide occurs just southwest of the Ranger Base Camp and is called the Base Camp landslide (fig. 1). The landslides were identified by Goff and others (1990) on their geologic map of the area. 


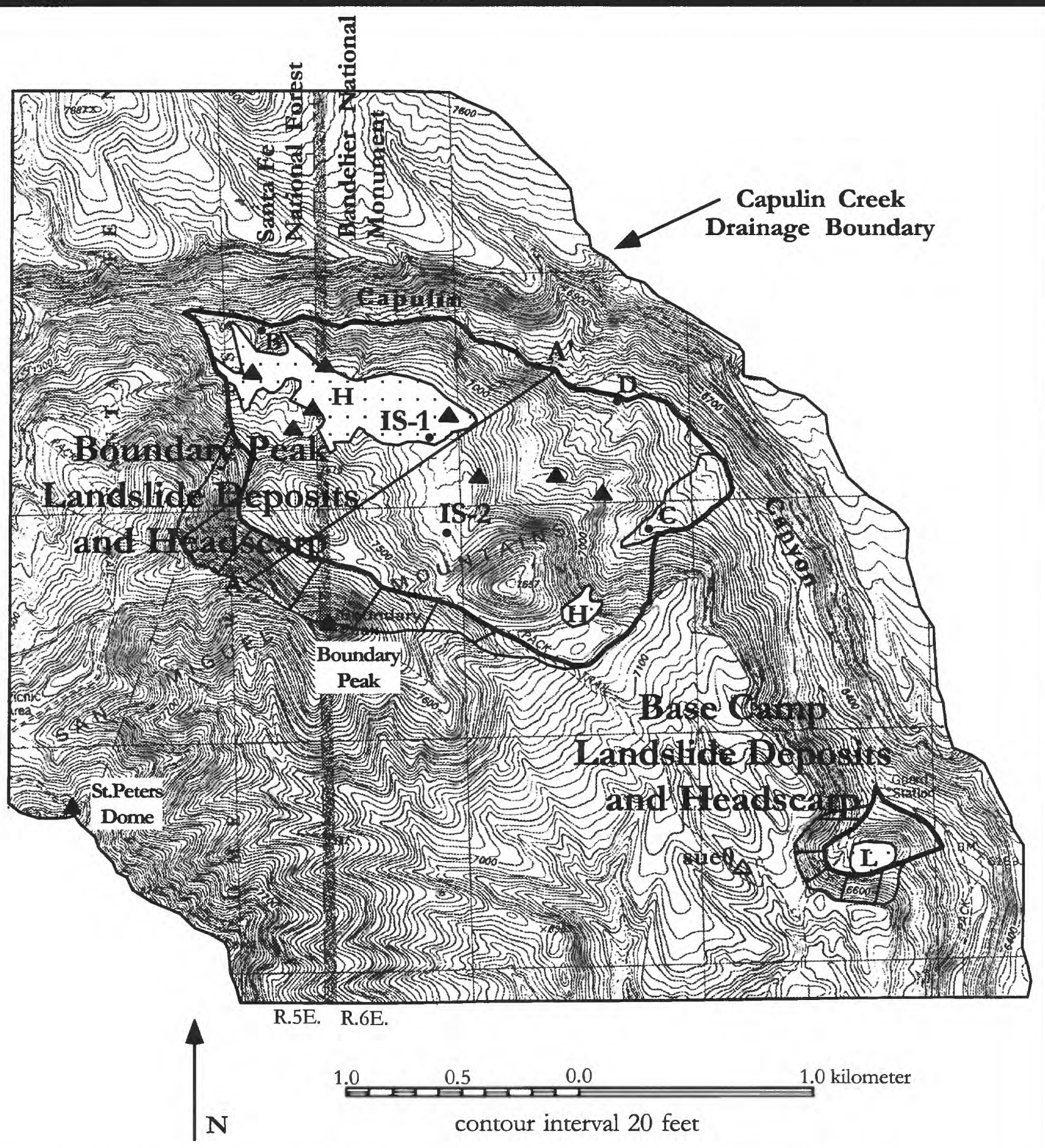

Figure 1. Topographic map of portion of Capulin Canyon in Bandelier National Monument showing locations of Boundary Peak and Base Camp landslide deposits, burn intensity, instrumentation sites, GPS survey monuments, and other locations discussed in the text. Stippled areas dentoe area of high $(\mathrm{H})$ burn intensity on the Boundary Peak landslide deposits, and an area of low (L) burn intensity on the Base Camp landslide deposits. Istrument site IS-1 is within the burned area, and IS-2 is in the unburned. Filled triangles show locations of GPS survey monuments; open triangle (sue0) shows location of reference base station. Letter B marks the location of a possible basal slip surface. Letter $C$ denotes the location of the alluvial fan wher ${ }^{14} \mathrm{C}$-dated samples were obtained. Letter D shows the location of surficial raveling of the landslide toe. Base is from U.S. Geological Survey Frijoles, New Mexico, 7.5' quardrangle. 


\section{Boundary Peak Landslide}

Deposits from the Boundary Peak landslide, as outlined in Figure 1, extend a distance of $1.2 \mathrm{~km}$ from the base of the headscarp to Capulin Canyon, and are approximately 2.4 $\mathrm{km}$ wide in the canyon. Delineation of the landslide deposits was accomplished through examination of the 1:8000-scale color IR aerial photographs taken on May 5, 1996, and field examination. The western and southwestern boundaries of the deposits were easily delineated based on topographic expression; the landslide deposits are generally smoother, and have gentler slopes than the adjacent undisturbed ground. The southeastern boundary, however, required a little more investigation. The 7657-foot-high peak located near the south margin of the landslide deposits is composed of Paliza Canyon Formation hornblende dacite that dips 55 degrees to the south with a N10W strike. This dip is considerably greater than that measured for the same unit to the south (Goff and others, 1990), and is oriented back toward the headscarp, suggesting that this peak is not inplace material, but rather a back-tilted rotational block that has moved downslope. The southeastern boundary of the landslide deposits was further located by what might possibly be the remnants of a flank ridge, a feature commonly found along the margins of actively moving landslides (Fleming and Johnson, 1989). In addition, a contact between the Bandelier Tuff and landslide material was observed just east of this flank ridge, and the remnants of rotational slump blocks in landslide material were observed on the slopes below. The northeast margin of the deposits was delineated based on the topographic expression of a steep landslide toe in Capulin Canyon.

The headscarp of the landslide developed in the volcaniclastic rocks of the Cochiti Formation, although the landslide itself may have also involved the Canovas Canyon Tuffs, the sandstones and siltstones of the Santa Fe Formation, and the Paliza Canyon Formation hornblende dacites, all of which make up the flanks of Boundary Peak. The present-day headscarp has an average slope of $70 \%$, although in places it is as steep as $86 \%$. Slopes vary from $9 \%$ on the surface of the landslide, to $50 \%$ on the steepest section of the toe where it rests in Capulin Canyon.

The surface of the landslide deposits is mantled by the El Cajete pumice from the youngest eruption of the Valles caldera about 50- to 60 ka (Reneau and others, 1996). A poorly-developed soil has formed in places in this loose, largely unconsolidated material. Note that strongly water-repellent conditions, a phenomenon commonly described following intense wildfire (for example, DeBano and Letey, 1969; Kalendovsky and Cannon, 1997) were observed at only one of eleven sites on the deposits examined by Cannon (1997).

According to a map of burn intensity prepared by the U.S Forest Service from 1:12,000-scale aerial photography taken after the fire and with limited field checking, the Boundary Peak landslide deposits experienced two areas of high intensity burn, both in stands of mature Ponderosa pine. These areas are shown as stippling on figure 1 , and cover a combined area of $0.15 \mathrm{~km}^{2}$. In these areas all pine needles, leaf litter, and branches up to $8 \mathrm{~cm}$ in diameter were consumed by the fire. Black and gray ash and charcoal deposits up to 5-cm deep were observed on the surface. The remainder of the deposits were mapped by the Forest Service as exhibiting moderate or low burn intensities.

What appears to be a basal failure zone of the Boundary Peak landslide is exposed in the west wall of a stream cut at map location $B$ (fig. 1). This zone was measured to be 84$\mathrm{cm}$ thick, is inclined at 3 degrees to the north, and consists of a plastic, silty clay of variable color. Laboratory determination of the Atterburg limits obtained a liquid limit of $61.5 \%$, plastic limit of $41.1 \%$ and a plasticity index of 20.4. This material would thus be classified using the Unified Soil Classification System as a silt of high plasticity (Craig, 1987). This possible failure surface rests on what appears to be red Galisteo sandstone. Given the location and geometry of the failure surface, and the slope of the headscarp, a possible location of the failure surface beneath the landslide can be inferred, as shown in cross-section A-A' (fig. 2). This reconstruction indicates that the deposits may be about $150 \mathrm{~m}$ thick. Given the impre- 


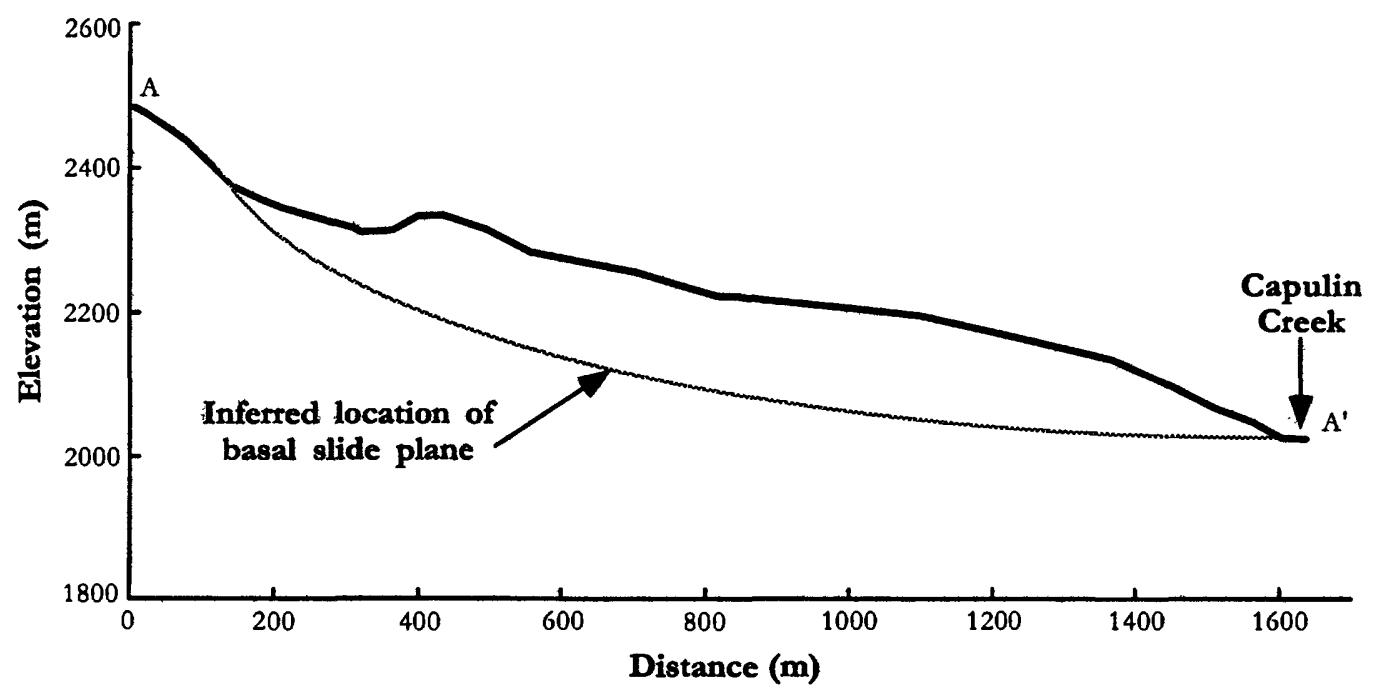

Figure 2. Cross section through Boundary Peak landslide deposits. Topography is from U.S. Geological Survey Frijoles 7.5' quadrangle.

cise values for the width and length of the deposits, a volume of the landslide deposits of approximately $530,000,000 \mathrm{~m}^{3}$ is calculated.

Movement of the Boundary Peak landslide likely occurred along a deep-seated, convexupward failure surface, which resulted in a rotational transfer of material downslope and out onto the valley floor. Material did not travel down Capulin Canyon for any distance. The topography of the landslide suggests that it moved primarily as one unit, although it appears that the main rotational block broke into a number of smaller, nested blocks at its lateral margins, resulting in a stepped topography on either side of the main block. No sedimentologic or geomorphic evidence was observed upstream from the landslide deposit that would indicate that the landslide ever dammed Capulin Creek, suggesting that the rates of movement into Capulin Creek were sufficiently slow to allow the creek to maintain a channel.

An alluvial fan is located on the southeast margin of the landslide deposits; its outline is shown on figure 1. This fan consists of fluvially reworked landslide material, as well as material eroded from the headscarp. The fan surface is covered with abundant open-work boulder and cobble berms. The materials that make up these berms are often imbricated, indicating a surface-water transport mechanism, and the berms themselves lack the matrix material necessary to identify them as debris-flow deposits. In addition to the fan surfaces, boulder berms have been deposited where drainages off the headscarp intersect the landslide deposits.

Incision into the fan surface at map location $\mathrm{C}$ by recent surface flows revealed a stratigraphy that indicates that fires have occurred on or near the landslide deposits in the past. The surface of the fan is blanketed with approximately $2.5 \mathrm{~cm}$ of ash and charcoal from the Dome fire. Beneath this, exposed in a 2.50-m-high cut, are two sequences of primarily water-lain sediments capped with thin layers that contain abundant ash and charcoal fragments. These ash- and charcoalrich units are interpreted as slack-water deposits associated with runoff events following fires located upslope in the drainage. The ${ }^{14} \mathrm{C}$ dates of A.D.1650-1950 and A.D. 12801630 were obtained from charcoal in the upper, and lower soils, respectively. We did not see any evidence of landslide response to these past fires.

\section{Base Camp Landslide}

The Base Camp landslide deposits, as outlined in figure 1 , extend $0.5 \mathrm{~km}$ from the headscarp to the canyon, and are $0.4 \mathrm{~km}$ 
wide at their broadest point. The landslide appears to have formed in the Upper Bandelier Tuff. The arcuate headscarp is as steep as $85 \%$, and the toe of the landslide also rests in Capulin Canyon, with a slope of $53 \%$. This landslide also failed as a single rotational unit that left deposits on the hillside and in the canyon. Material did not travel down Capulin Canyon. No sedimentological evidence was observed upstream from the landslide deposit that would indicate that the landslide ever dammed Capulin Creek, suggesting that the rates of movement into Capulin Creek were sufficiently slow to allow the creek to maintain a channel.

One area of low burn intensity that covers approximately $0.03 \mathrm{~km}^{2}$, or one-sixth, of the deposits is shown on the U.S. Forest Service map of fire intensity (fig.1).

\section{PRESENT STABILITY OF LAND- SLIDE DEPOSITS}

\section{Both the Boundary Peak and Base Camp} landslide deposits are mantled the El Cajete pumice; geochronologic data suggests an age of about 50 to $60 \mathrm{ka}$ for this deposit (Reneau and others, 1996). The superposition of the pumice on the landslide deposits indicates a minimum age of 50,000 to 60,000 years for the last significant movement of the landslides. The entire landslide topography is muted and subdued, also indicating an advanced age, and lack of recent movement. We observed no cracks, fissures, or shear zones, or any other signs of instability on the landslide deposits. Although the thickness of the pumice mantle on the landslide deposits is unknown, the weathering of the pumice and degree of soil development is sufficient such that reactivation of the underlying landslide deposits could be reflected at the surface. Although our proposal suggested installing photographic-monitoring sites on the landslide deposits, this lack of evidence of active movement or unstable ground made it impossible to select sites for monitoring that would give informative results.

A few tilted trees were observed on the landslide deposits but they are too few and far between to indicate instability. The tilting of the few trees we observed can be explained as a phototropic response (Phipps, 1974), and a grouping of contiguous, similarly-aged tilted trees is necessary to indicate landslide instability.

The interaction of Capulin Creek and the toes of the landslides appears to be negligible, and no danger of destabilization- of the deposits by incision appears to exist at this time. The stream bed of the creek in Capulin Canyon is quite broad and flat, and is not constricted by either of the landslide toes at this time. At one location (map location D) the steep front of the Boundary Peak landslide toe has failed as a surficial slip. The approximately $1-\mathrm{m}$-high scarp is subtle and smoothed by erosion, indicating that this is not a recent feature. The slip is approximately 15-m wide and 3-m high. The recent flooding on Capulin Creek has, however, incised slightly into this raveling surface, resulting in a 2-m- high cut into the channel bank. This was the only interaction of Capulin Creek with the either of the toes of the landslides observed in the canyon bottom, and its scale precludes any threat of destabilization of the landslide mass.

\section{Global Positioning System Survey}

A network of survey monuments was installed on the landslide deposits in July of 1997 for a GPS-based movement-detection system. Locations of the monuments are shown as triangles in figure 1. The 1997 GPS survey was made using three Ashtech Z-12 dual-frequency receivers and rapid-static survey technique which involves ten to thirty minute site occupations. The data were reduced using Ashtech's PNAV software (v. 2.4.0M) with forward processing running under DOS on a notebook PC. Processing for the survey array used the reference base station labeled sue0 on figure 1. Control was established using static survey techniques between a known Cooperative Base Network Control Station located at Technical Area 33, Los Alamos National Laboratory (National Geodetic Survey point F01671, Los Alamos National Laboratory survey marker 1709 5-62). Relative positional accuracy of the survey monuments should be on the order of $0.02 \mathrm{~m}$ in the horizontal and $0.03 \mathrm{~m}$ in the vertical. 
Only one survey of the array has been completed; repeated surveys will be necessary to determine and monitor movement of the landslide deposits.

\section{SOI-MOISTURE MONITORING}

This phase of the evaluation addresses the issue of a potential change in stability of the landslide mass due to the removal of vegetation. This analysis is based on the assumption that the only variable altered by the fire that affects the stability of the landslides is the infiltration of rainfall and snowmelt into the slide mass at the surface. Presumably, any other deep water source and the internal hydrologic characteristics of the mass were not altered by the fire. Two possible effects of the fire are: (1) a change in infiltration rates and amounts of rainfall and snowmelt as a result of removal of the mulching litter on the ground surface; and (2) a change in the rates and amounts of rainfall that can infiltrate to depth because of the decreased transpiration rates of the burned trees. To address these issues, two soil-moisture monitoring sites were established, one on the burned slide mass, and the other on similar unburned terrain. Each site consists of a tipping bucket rain gage and two sets of four soil-moisture sensors installed to determine negative soil pore-water pressures, that is, soil tensions, at varying depths. This configuration was designed to document the infiltration of rainfall into the soil during summer thunderstorm events.

Soil tension is a measure of the forces holding soil moisture to the soil structure. When the soil is very dry, the small amount of inter-particle water in the voids is bound tightly to the soil particles. As the inter-particle voids in the soil are filled with moisture, the overall forces binding the moisture to the grains is lessened. Thus, in the simplest sense, lower soil tension values indicate a higher moisture content. Note, however, that the relation between soil tension and volumetric water content for silt and fine sand is not linear, but rather resembles a flattened-S shaped curve, as determined experimentally and shown in figure 3 . The form and position of the curve depends on the grain-size distribution of the soil, or better yet, the poresize distribution (Burdine, 1953). As represented by the tails of the S-shaped curves, the change in volumetric water content becomes negligible at varying values of soil tension, depending on the materials. Although the form of this moisture-retention curve is unknown for the materials at the instrument sites without further testing, grain-size analyses of the site materials indicates a silty sand to sandy gravel texture. For such materials, the change in volumetric water content can be considered to be negligible for soil-tension values less than $-50 \mathrm{kPa}$.

\section{Instrumentation}

Watermark model 200SS soil-moisture sensors, manufactured by lrrometer Company, Inc. of Riverside California, were selected for monitoring soil-pore water tension conditions at each site. The sensors consist of two concentric electrodes embedded in a granular matrix which has a consistency similar to fine sand. Included in the matrix is a gypsum block which minimizes any effects of soil salinity on electrical conductivity. These granular-matrix sensors were developed in the early 1980's, and have been used extensively in the agricultural industry for irrigation monitoring and control.

For purposes of this investigation, the granular-matrix sensors offer several advantages over other possible soil-moisture instrumentation. The cylindrical sensors, having dimensions of $2.25 \mathrm{~cm}$ in diameter and $8 \mathrm{~cm}$ in length, are easily installed in small-diameter hand-augered holes at various depths in the ground with a minimal disturbance of the existing soil column. Careful backfilling and tamping of the emplacement hole minimizes the possibility that it may provide an avenue of increased permeability for surface water to migrate to the sensors, although this possibility cannot be eliminated entirely. Other methods, such as TDR (time-domain reflectometry) or gypsum block sensors, would require greater disturbance of the overlying and surrounding soil column for emplacements of the sensing elements, and minimal disturbance of the natural soil column was considered to be a critical concern for this 
study. Further, the granular-matrix sensors can be placed in the ground for long periods of operation (even freezing) with no maintenance, and the cost is low relative to other instruments.

Additional instrumentation at each of the sites includes a tipping bucket rain gage capable of measuring rainfall in increments

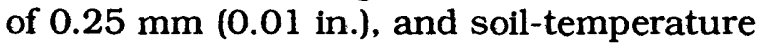
sensors with an accuracy of $\pm 1{ }^{\circ} \mathrm{C}$ installed at $15 \mathrm{~cm}$ and $61 \mathrm{~cm}$ depths. The soil-temperature sensors were installed to provide temperature correction in converting soil-sensor output to soil-tension values.

Data from the rain gages, soil-moisture sensors, and temperature sensors at each site are monitored and recorded by a datalogger/cellular telemetry system marketed by Environmental Cellular Inc. of.Boulder, Colorado. The data recording and acquisition systems allow for data retrieval by remote computer dial-in. As currently configured, the systems record rainfall totals for six hour intervals, and the soil-moisture and temperature readings every six hours. In the event of accumulated rainfall that exceeds $2.5 \mathrm{~mm}$ (0.1 in.) in any 6 hour recording interval, the systems switch to a fast-record mode wherein rainfall totals, soil moisture, and temperature readings are recorded every 15 minutes for the following 6 hours. The systems then return to the slow-record mode. This configuration allows for the rapid recording of soilmoisture conditions during significant rainfall events, and results in the savings of significant data storage space.

\section{Soil-Moisture Sensor Calibration}

The granular-matrix soil-moisture sensors provide an indirect measure of soil-water tension, and thus a series of calibrations are necessary to convert the sensor output to soil-tension values as a function of temperature.

Comprehensive research into the calibrationof the Watermark sensors has been done at the Malheur Experimental Station which is operated by Oregon State University at Ontario, Oregon. Here, the Watermark sen- sors have been tested in both lab and field environments (for example, Eldredge and others, 1993; Shock and Barnum, 1992; Stieber and Shock, 1995). The field calibration of Watermark sensors determined by Eldredge and others (1993) is based on a comparison of sensor output to tensiometer readings, and produced a linear relationship between sensor output and soil tension. This relation is defined in the range between 0 to $-80 \mathrm{kPa}$ for 79 data points with an $\mathrm{r}^{2}$ of 0.89 . The relationship of soil tension to sensor output derived by Eldrege and others (1993) is:

$\psi=-6.44-0.738 x$ eqn. 1

where $\psi$ is soil-water tension in negative $\mathbf{k P a}$ and $x$ is the reading obtained with the 30KTCD meter supplied by the manufacturer for reading the sensor output. The 30KTCD meter is designed such that the meter readings are related to sensor resistance and temperature by the equation:

$$
x=\frac{R-0.5}{0.1759(1-0.013 T)} \quad \text { eqn. } 2
$$

where $\mathrm{R}$ is resistance in $\mathrm{k} \Omega$, and $T$ is temperature in ${ }^{\circ} \mathrm{C}$. By substitution of equation 2 into equation 1 , the relation between soilwater tension and sensor resistance and temperature is:

$$
\psi=-6.44-\frac{4.20(R-0.5)}{(1-0.013 T)} \quad \text { eqn. } 3
$$

Interface circuitry to convert a $12 \mathrm{v} D C$ power source to provide $5 \mathrm{v}$ AC excitation voltage to the soil-moisture sensors was built by the datalogger supplier. Because the sensors are an electrical resistive device, it is necessary to calibrate the sensors and interface circuitry to the datalogger output. To accomplish this calibration known resistances were applied to each analog input and the corresponding datalogger output in analog-to-digital counts recorded. This calibration resulted in a nonlinear relationship of the form:

$R=\frac{0.0188 C^{2}+11.288 C}{1000} \quad\left(\mathrm{r}^{2}=0.98\right) \quad$ eqn. 4

where $R$ is resistance in $\mathrm{k} \Omega$ and $C$ is datalogger output in counts. Substitution of equation 4 into equation 3 provides the following 
relationship for soil-water tension (in negative $\mathrm{kPa}$ ) as a function of datalogger output and temperature:

$$
\psi=\frac{-4.34+0.084 T-7.90 \times 10^{-5} C^{2}-0.047 C}{1-0.013 T} \quad \text { eqn. } 5
$$

Note that although the Watermark sensors can respond to soil tensions well beyond the range of the data used in the calibration (between 0 and $-80 \mathrm{kPa}$ ), it would not be appropriate to extrapolate the curves to these higher tension values. For this reason, only data in the range of 0 to $-80 \mathrm{kPa}$ are considered in this study. This constraint poses no serious limitations as soil tensions in excess of $-50 \mathrm{kPa}$ are measured in soils that can experience very little changes in water content (fig. 3).

And lastly, in order to quantify the soil-moisture response, or to convert soil-tension values to volumetric water contents and permeabilities, further testing is necessary to establish the soil-moisture retention curves for the site materials (for example, vanGenuchten, 1980; Brooks and Corey, 1966). Further complicating the issue of determining volumetric water contents from soil tension values, repeated wetting and drying cycles experienced by the soil result in a hysteresis in the soil water retention curve.

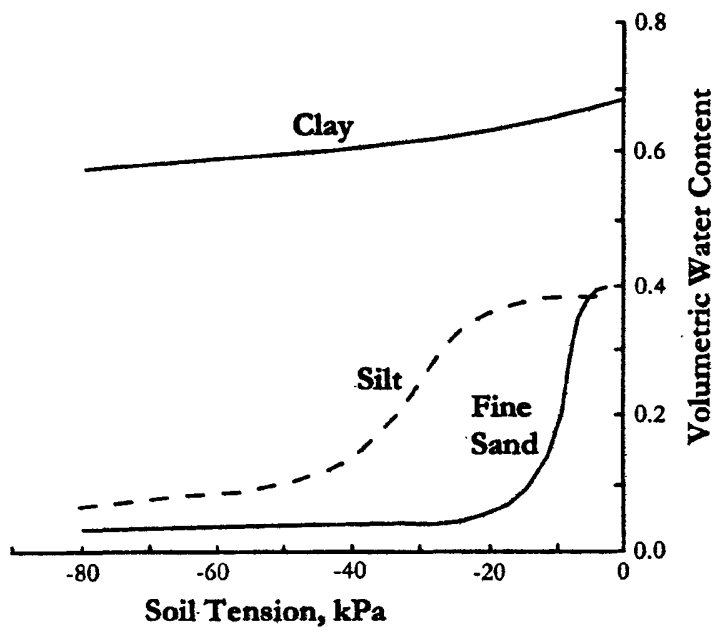

Figure 3. Soil water retention curves for clay, silt, and fine sand.
Laboratory testing of soil permeability characteritics may be necessary to quantify this relation for the situation on the landslide deposits.

\section{Instrument Locations and Installations}

The location of the two soil-moisture monitoring sites (IS- 1 and IS-2) on the Boundary Peak landslide deposit are shown in figure 1. Site IS- 1 is located in an area that experienced a high burn intensity, and as a result is very open and exposed to sunlight. The surface is mantled by an unknown thickness of the El Cajete pumice. The ground surface at site IS-1 slopes 3 degrees to the northeast, and the character of the subsurface materials was examined by digging a shallow pit and by augering with a $6.35 \mathrm{~cm}$ auger bit to a depth of $122 \mathrm{~cm}$. The following materials and characteritics were revealed:

\section{Site IS-1:}

(in centimeters)

0-4 dry ash, charcoal and pumice frag ments

4-8 dry, light tan silty sand with pumice fragments

8-30 moist, light brown silty sand with pumice fragments

30-61 slightly moist, light brown silty sand with pumice fragments

61-86 slightly moist, light tan silty sand with pumice fragments

86-122 dry, white ignimbrite interbed

The fire intensity map prepared by the U.S. Forest Service shows the location of Site IS-2 in a moderately burned area. Field evidence, however, indicates that fire swept through the area, but with a very low temperatures and a short residence time; some ponderosa pine trunks are singed to a height of $91 \mathrm{~cm}$, but the needles remain green, the bark is healthy, and old pine needles remain on the ground. We thus consider this an essentially unburned site. Site IS-2 is considerably shadier than IS-1 due to the presence of abundant living ponderosa pine. The ground surface slopes 3.5 degrees to the northnortheast, and although it is also mantled with El Cajete pumice, some cobbles and 
Table 1. Soil-moisture sensor number and installation depth information at sites IS-1 and IS-2. Soil temperature sensors at each site are installed at depths of 15 and $60 \mathrm{~cm}$.

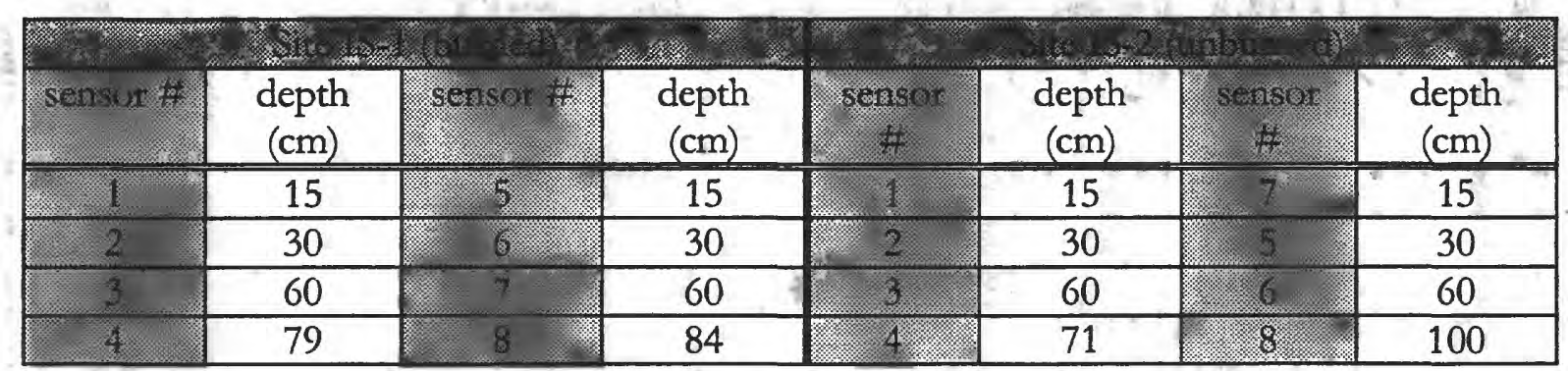

small boulders derived from the headscarp are scattered on the ground surface. The subsurface materials were examined by augering to a depth of $91 \mathrm{~cm}$. The following materials and characteristics were described:

Site IS-2:

(in centimeters)

0-15 dry, light tan silt

15-38 moist, light brown silty clay with pumice fragments

38-53 moist, lightly oxidized, light brown silty sand with pumice fragments

53-91 dry, light tan silty sand with some white ignimbrite fragments

It was more difficult to remove material from the auger tip at this site than at IS-1, presumably due to a slightly higher clay content of the materials. Grain-size distribution testing is presently underway to quantify the differences between the two sites.

Note that strongly water-repellent conditions, a phenomenon commonly described following intense wildfire for example, DeBano and Letey, 1969; Kalendovsky and Cannon, 1997) were not observed at either of the instrumentation sites.

Figures $4 \mathrm{~A}$ and $4 \mathrm{~B}$ are sketch maps showing the location of the soil-moisture sensor emplacement holes, temperature sensor emplacement holes, rain gages, dataloggers, and solar panels at each instrumentation site. The depths of installation of the soilmoisture sensors at each site are listed in table 1 . The depth to which the deepest sen- sors were installed was controlled by the presence of unweathered pumice. Note also that sensors 5 through 8 at site IS- 2 are not in the same sensor number-depth sequence as the other array due to installation constraints.

The raingages and soil-monitoring instrumentation were installed in late August of 1996 and have operated nearly continuously since that time. Soil-temperature sensors were installed in early September of 1996 allowing calculation of soil-tension values. Note that the temperature sensors were installed at depths of 15 and $61 \mathrm{~cm}$. Temperature data from the sensor at $15 \mathrm{~cm}$ was used in the calibration of soil-moisture sensors at $15 \mathrm{~cm}$, and the temperature probe at $61 \mathrm{~cm}$ was used for all other soil-moisture sensors. Except for an approximately two-week period in late October and early November of 1996 during which solar power problems were encountered at IS-2, and a 1-week period in September of 1997 when the site was vandalized, essentially continuous records of rainfall and snowmelt events and soil-moisture conditions have been recorded at both sites.

Note that the soil-moisture sensors are installed in the ground wet and surrounded by a slurry of the soil in which they are installed. The slurry insures that air pockets are eliminated so that good contact between the soil and sensor is established. Some period of time is therefore required for the natural soil-moisture conditions in the proximity of the sensors to return to equilibrium, the length of which depends on the water 







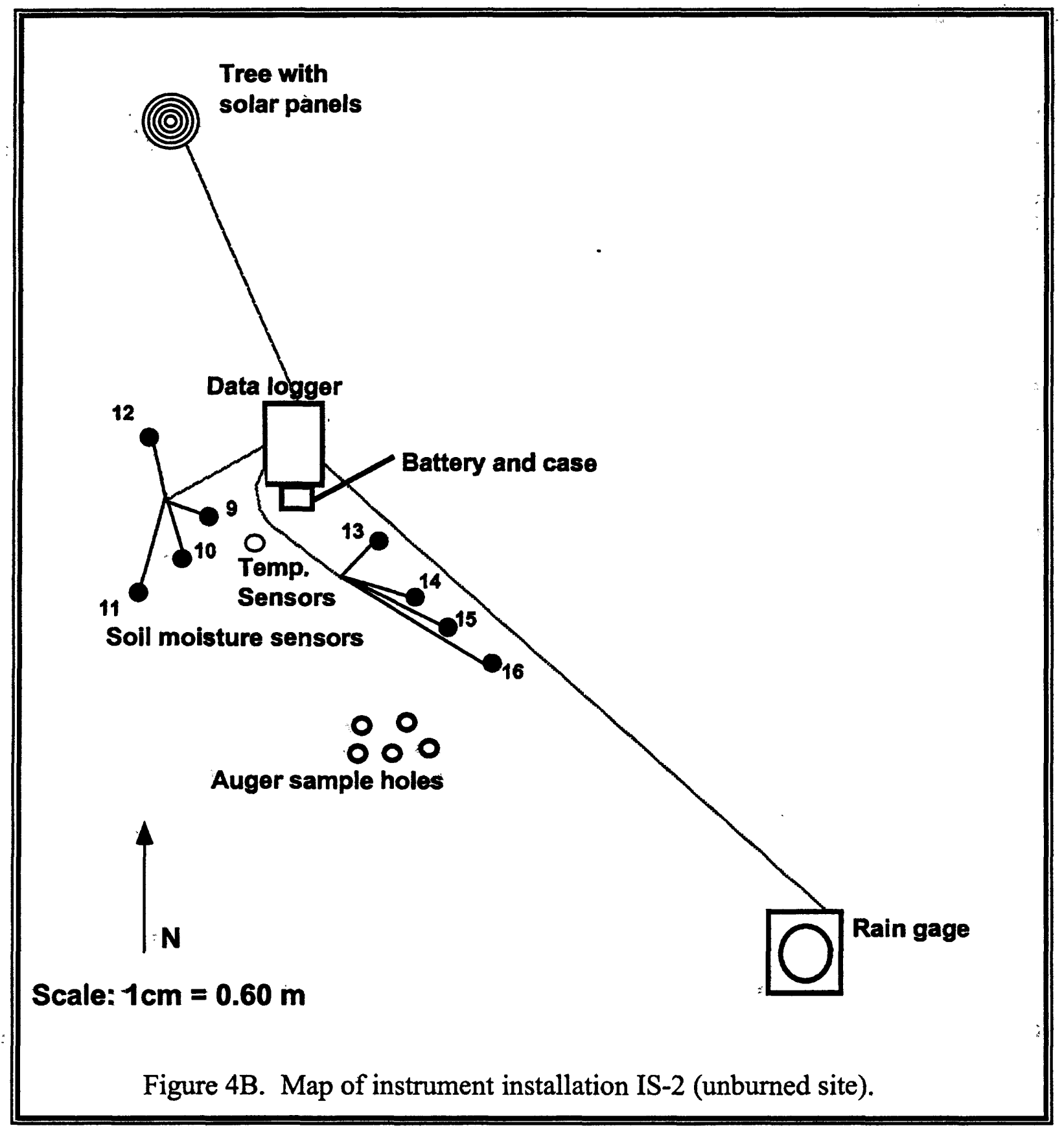


content and properties of the surrounding soil. The soil surrounding the sensors was considerably drier than the installation slurry and thus a period of drying was expected following sensor installation.

\section{Results}

A qualitative comparison of the soil-tension responses of the burned and unburned sites (figs. 5 and 6 , respectively), recorded from September 10 to November 30,1996, and from December 30, 1996 to December 30, 1997 (figs. A and B, respectively) indicates relations somewhat different than those described in Cannon and Ellis (1997), which were based on interpretation of the response to three discrete rainfall events following the summer monsoon season. The comparison presented below yields two primary relations: (1) over time, and with continued rainfall, moisture infiltrates to greater depths at the burned site than at the unburned site, and 2) even though the burned site is very open and exposed to direct sunlight, the soil at this site stays relatively moist throughout the summer monsoon season, while the more shaded unburned site dries out rapidly with the onset of warm temperatures.

The rainfall records for 1996 and 1997 show similar rainfall accumulations at both of the two sites (figs. 5A and B, 6A and $\mathrm{B}$ ).

Following the installation of the instruments in late August of 1996, three primary periods of rainfall accumulation were recorded: one in mid-September (from the 12th through the 19 th), another in early October (on the 4th and 5th), and lastly, one in late October (from the 23rd through the 29th). The rainfall record for 1997 also included the summer monsoon season. A number of small storms occurred between early February and late June, followed by a relatively dry period until mid-July. Rain then fell nearly continuously until late August. Similar to the 1996 season, three discrete rainfall events then occurred; these being in early September (from the 6th through the 10th), late September 9 (from the 20th through the 22nd), and in mid-November (from the 10th through the 17 th). The following describes the response of the soil-moisture sensors at the burned and unburned sites to this rainfall record.
Burned Site Response: The record for 1996 , as shown in figure $5 \mathrm{~A}$, reflects a gradual movement of soil moisture to greater depths with a continued application of rainfall. In response to the second period of rainfall (starting on September 14th) during the September event, both of the $15 \mathrm{~cm}$ sensors show a rapid wetting, which was then followed by a period of gradual drying. The remaining sensors either continued to dry, or did not respond. The October 4-5 event was characterized by an immediate wetting of both the $15 \mathrm{~cm}$ sensors, followed about 12 hours later by sensor ST-7 at $60 \mathrm{~cm}$. Again, this response was followed by a gradual drying, and the remaining sensors continued to dry or did not respond. The October 23-29 rainfall and snowmelt event showed an immediate wetting of the two $15 \mathrm{~cm}$ sensors, followed about 4 days later by wetting of sensor ST-7 at $60 \mathrm{~cm}$, which was followed one day later by sensor ST-3 at $60 \mathrm{~cm}$, and lastly, two days later, by the $84 \mathrm{~cm}$ sensor. The remaining sensors showed no response.

The soil-moisture data for 1997, shown in Figure 5B, also reflects a gradual infiltration of soil moisture to depth with the continued application of rainfall. From the start of the record until early March, the record is characterized by the drying and wetting of both the $15 \mathrm{~cm}$ sensors that accompanied freezing and thawing of the upper soil surface. The deeper sensors did not show this effect. Then, starting in mid-March and continuing. until late June, both $15 \mathrm{~cm}$ sensors showed immediate wetting at the onset of each small rainfall event, followed by a more gradual period of drying. Sensor ST-6 at $30 \mathrm{~cm}$ remained constant through this period, and the other was extremely dry. Of the $60 \mathrm{~cm}$ sensors, ST-7 remained constant, while ST-3 showed a wetting response in late April. Oddly, although neither of the $30 \mathrm{~cm}$ sensors registered any effects of these rainfall events, the $79 \mathrm{~cm}$ sensor does show a wetting response. There are two possible explanations for this phenomenon: either the wiring was switched during installation and the channel thought to be reading the $79 \mathrm{~cm}$ sensor is actually reading the $30 \mathrm{~cm}$ sensor, or an inter-soil channel is directing moisture to this deeper sensor. This issue can possibly be resolved when the sensors are removed from the ground. Continuing on, 


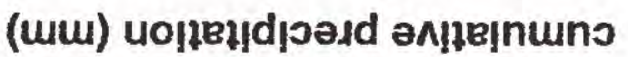

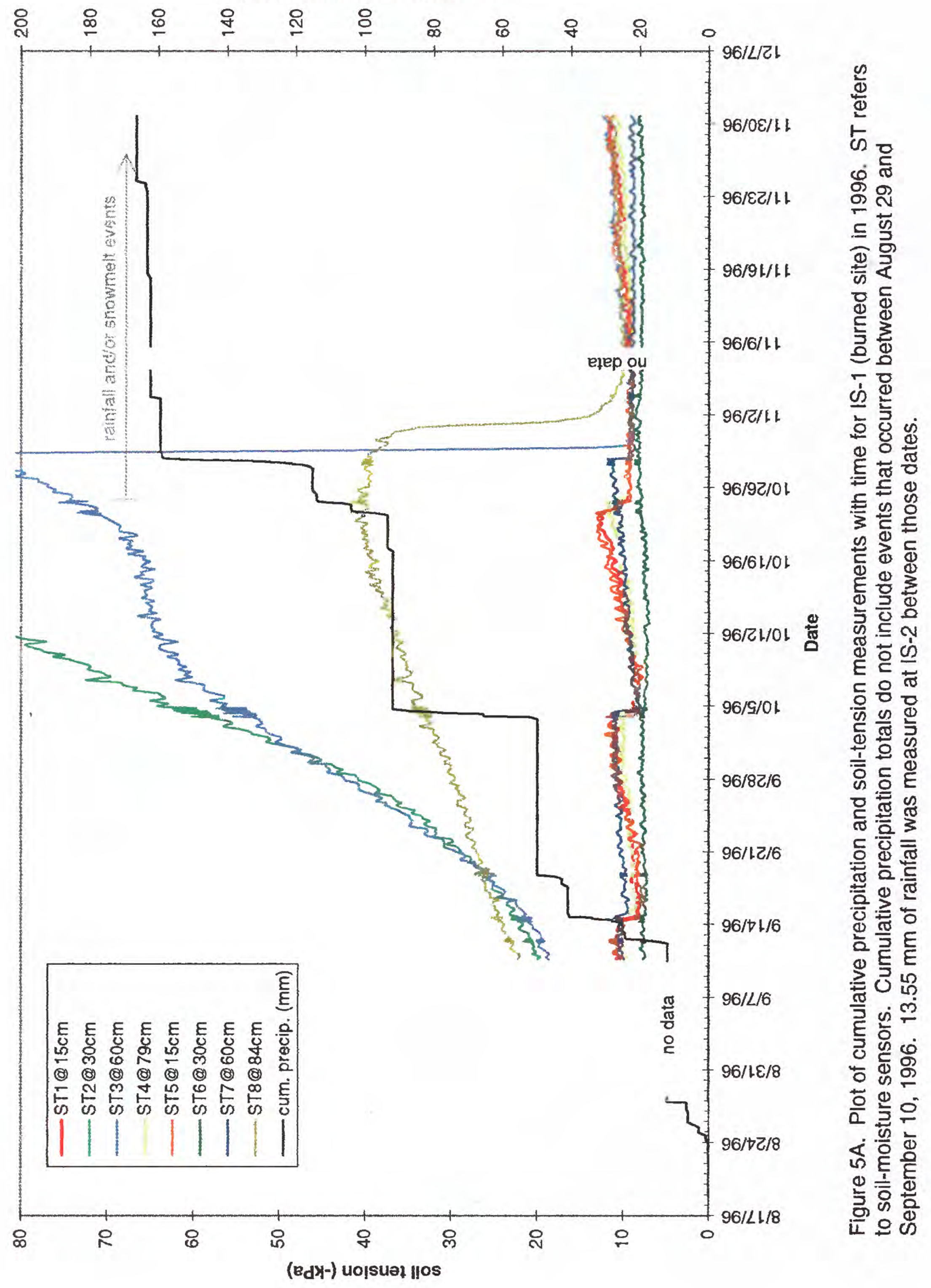




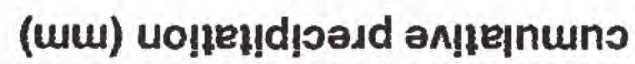

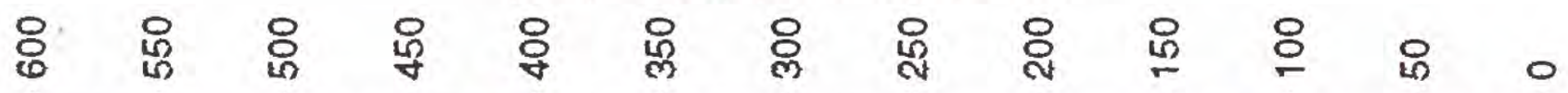

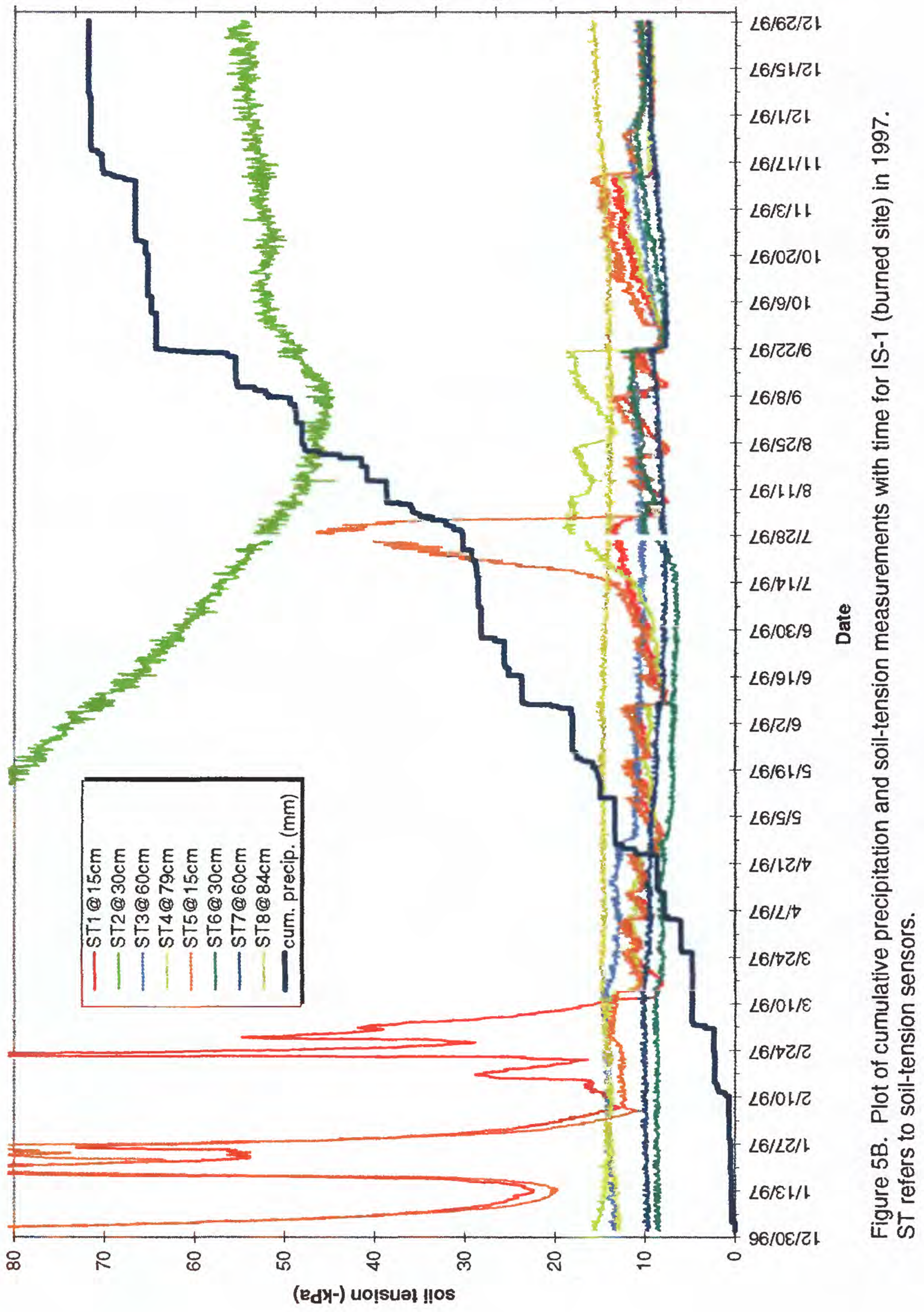


(uw) uo!neџ!d!

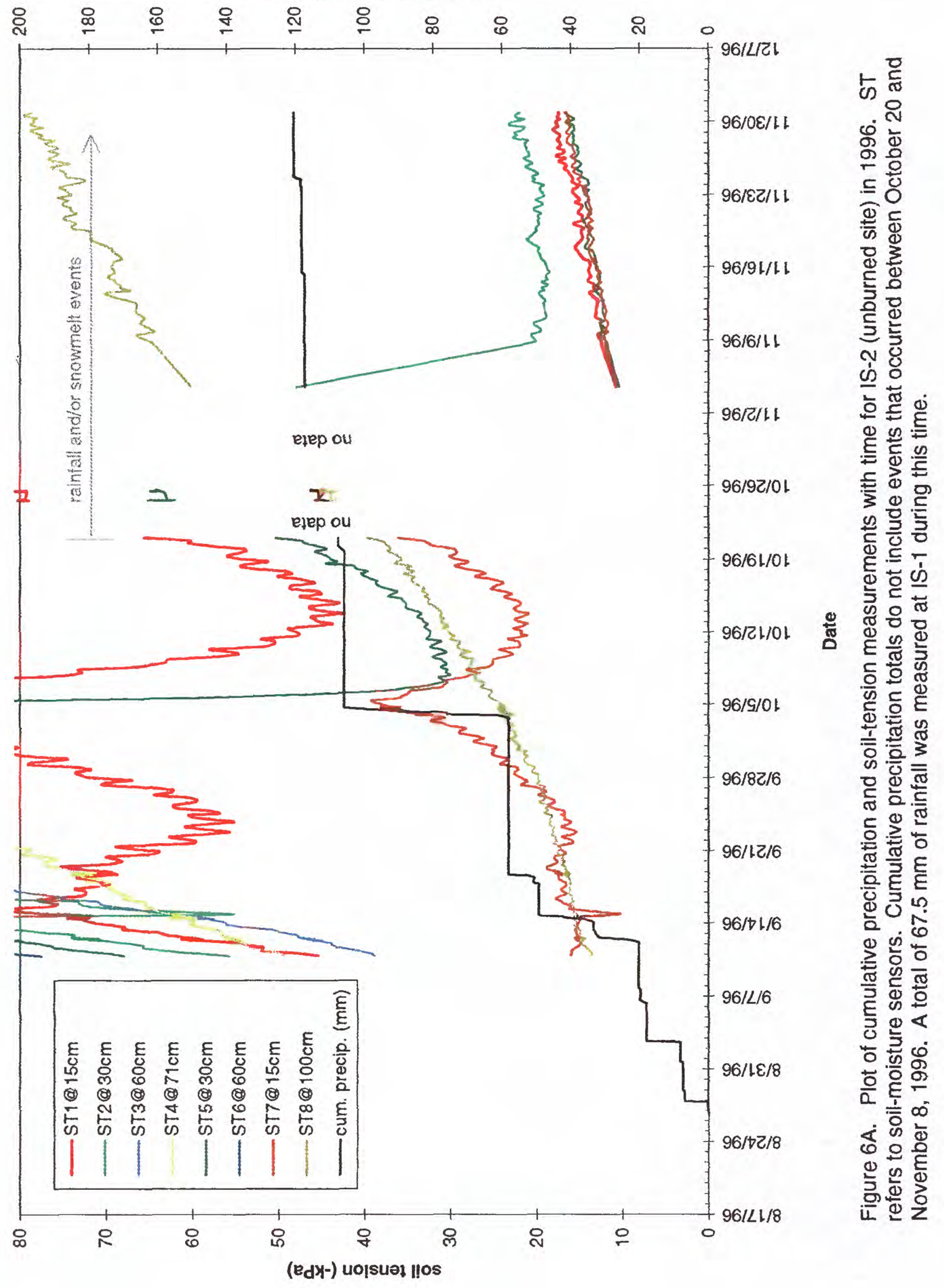




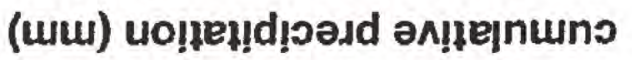

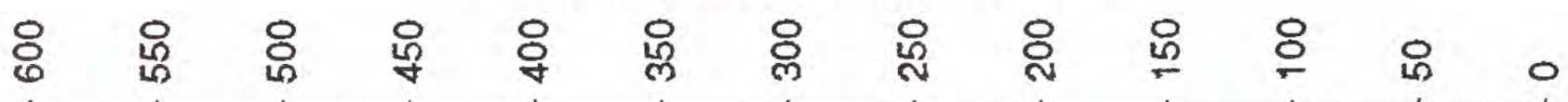



(edy-) uoḷsuə\} ॥os 
during the dry period between late June and mid-July, the two $15 \mathrm{~cm}$ sensors and the presummed-79 $\mathrm{cm}$ sensor, followed by sensor ST -6 at $30 \mathrm{~cm}$, show a gradual drying. The onset of the rainy period in mid-July is accompanied by an immediate wetting of both $15 \mathrm{~cm}$ sensors, which then continue to gradually dry and then wet up in response to lulls and periods of rainfall accumulation. Sensor ST-6 at $30 \mathrm{~cm}$ showed a gradual drying during this period, followed by a constant value. The dry period between late August and early September shows a gradual drying of the sensors that had wetted during the preceding rainy period. The September 6-10 storm resulted in the re-wetting of both the $15 \mathrm{~cm}$ sensors, but no response of the deeper sensors. Even the errant $79 \mathrm{~cm}$ sensor did not register this event. However, the

September 20-22 storm resulted in an immediate wetting of both $15 \mathrm{~cm}$ sensors, sensor ST -6 at $30 \mathrm{~cm}$, both $60 \mathrm{~cm}$ sensors, and the $79 \mathrm{~cm}$ sensor. This was again followed by a period of gradual drying until the final storm of the season in mid-November. Both the $15 \mathrm{~cm}$ sensors responded immediately to this event, followed a few days later by sensor ST3 at $60 \mathrm{~cm}$ and a little later still, by sensor ST -6 at $30 \mathrm{~cm}$.

The drying responses of the sensors described above also reflect an important characteristic of the burned site. Although the sensors show a gradual drying between rainfall events, the minimum values of soilwater tension attained are, in general, around $-15 \mathrm{kPa}$. This fact that this minimum value is small relative to those measured at the unburned site (described below), indicates that this site remains relatively moist throughout the summer. This is a particularly interesting result given that the burned site is relatively open and exposed to direct sunlight, while the unburned site is well shaded.

Unburned Site Response: Data from the soil-moisture sensors through 1996, shown in figure 6A, illustrate a response to rainfall events quite different from that of the burned site. During the second period of rainfall within the September 12-19 event, sensor ST-7 at $15 \mathrm{~cm}$ showed a relatively rapid wetting. A period of gradual drying was then ended by a rather gradual wetting of both the $15 \mathrm{~cm}$ sensors and sensor ST -5 at $30 \mathrm{~cm}$ in response to the early October rainfall. A gap in the data exists due to power difficulties in mid-October. However, when data acquisition resumed, both $15 \mathrm{~cm}$ sensors and sensor ST -5 at $30 \mathrm{~cm}$ were relatively moist. The soil-moisture data for the unburned site from 1997, shown in figure $6 \mathrm{~B}$, show a response remarkably different from that of the burned site. The record again shows a response to repeated freezing and thawing by both $15 \mathrm{~cm}$ sensors from the start of the record to mid-March. The two $30 \mathrm{~cm}$ sensors did not respond to this effect, and the remaining sensors are so dry as to be off the vertical axis. As with the burned site, both $15 \mathrm{~cm}$ sensors show a rapid wetting followed by a more gradual drying response to rainfall starting in mid-March. In contrast with the burned site, however, both $30 \mathrm{~cm}$ sensors also show this response, although it is less rapid and uniform than is that of the $15 \mathrm{~cm}$ sensors. More importantly, however, and again in contrast with the burned site, at the end of April all four sensors start to dry out quickly and stay dry for the rest of the summer (with the brief exception of dramatic responses to rainfall events in late September and mid-November). Values for soil-water tension are considerably drier than the average value of $-15 \mathrm{kPa}$ measured at the burned site.

\section{Discussion}

The comparison of the soil-moisture response to rainfall between the burned and unburned sites presented here yields two primary relations: (1) over time, and with continued rainfall, moisture infiltrates to greater depths at the burned site than at the unburned site, and (2) the soil at the burned site stays relatively moist throughout the summer monsoon season, while the unburned site dries out rapidly with the onset of warm summer temperatures. Given that the burned site is relatively open and exposed to direct sunlight, while the unburned site is rather shaded, these pronounced differences may indicate that transpiration by the living Ponderosa pine at the unburned site plays a considerable role in removing moisture from the soil 
during the summer months. As $60 \%$ of the annual precipitation falls between June and September (Allen, 1989), this effect may have a considerable consequence on the soil-moisture budget of the landslide deposits. Note, however, that further evaluation is necessary to determine if the increased infiltration is are sufficient to result in the destabilization of the landslide deposits.

These findings contrast with those of Zwolinski (1971) and Campbell and others (1977), who examined the influence of fire on water infiltration capacities in Ponderosa pine ecosystems in Arizona. Both papers concluded that infiltration capacities decreased significantly following severe burns, and attributed this decrease to the possible presence of water-repellent soils. (Water-repellent soils were not detected at either of the two sites used in this study.) Zwolinski (1971) describes infiltration capacities restored to nearly normal conditions after one winter, while the data presented here illustrates a considerable disparity between infiltration characteritics of the burned and unburned sites well after one winter.

\section{SUMMARY AND CONCLUSIONS}

To assess the present stability of the Boundary Peak and Base Camp landslides in Capulin Canyon, and to evaluate the potential for destabilization due to the removal of vegetation during the Dome fire, a program of mapping and soil moisture monitoring was undertaken.

The Boundary Peak landslide covers an area of approximately $2.9 \mathrm{~km}^{2}$, and appears to be approximately $150 \mathrm{~m}$ thick, while the Base Camp landslide covers approximately $0.2 \mathrm{~km}^{2}$. The thickness of the Base Camp landslide deposits is not known. The Boundary Peak landslide deposits experienced two areas of high burn intensity which cover a total area of approximately $0.15 \mathrm{~km}^{2}$. The remainder of the deposits were mapped as moderate or low burn intensities. The Base Camp deposits show one area of low burn intensity which covers an area of 0.03 $\mathrm{km}^{2}$. Initial emplacement of both the Boundary Peak and Base Camp landslide deposits occurred along deep-seated, convexupward failure surfaces, which resulted in a rotational transfer of material downslope and out onto the valley floor. Material from either landslide did not travel down Capulin Canyon for any distance. No sedimentological evidence was observed upstream from the landslide deposits that would indicate that the landslides ever dammed Capulin Creek, suggesting that the rates of movement into Capulin Creek were sufficiently slow to allow the creek to maintain a channel.

Neither the Boundary Peak or the Base Camp landslide deposits exhibit evidence of recent movement or instability. Both landslide deposits are mantled by the El Cajete pumice, giving a minimum age of 50,000 to 60,000 years for the latest significant movement of the landslides. The entire landslide topography is muted and subdued, no cracks, fissures or shear zones were observed, and only a few tilted trees, too few and far between to indicate instability of the deposits, were observed. Although the thickness of the pumice mantle on the landslide deposits is unknown, the weathering of the pumice and degree of soil development is sufficient such that reactivation of the underlying landslide deposits could be reflected at the surface. The interaction of CapulinCreek and the landslide toes appears to be negligible, and no danger of destabilization of the deposits by undercutting appears to exist at this time.

The likelihood of reactivation of the Base Camp landslide deposits due to increased infiltration in areas burned by the Dome fire appears to be negligible due to the small area and low intensity of the fire on the deposits.

Qualitative evaluation of the soil-moisture data from the Boundary Peak landslide deposits indicates an increase in rainfall and snowmelt infiltration at the burned site, suggesting that removal of vegetation by the Dome fire could possibly affect the stability of the deposits. The evaluation indicates that (1) over time, and with continued rainfall, moisture infiltrates to greater depths at the burned site than at the unburned site, and (2) the soil at the burned site stays rela- 
tively moist throughout the summer monsoon season, while the unburned site dries out rapidly with the onset of warm temperatures. These differences appear to be due to the lack of vegetation-induced transpiration at the burned site.

Further evaluation is necessary to determine if the increased infiltration is sufficient to result in the destabilization of the landslide deposits. Movement on this type of deepseated landslides is precipitated by infiltration of water deep into the deposits. Either a number of consecutive, very wet rainfall seasons, a single large snowmelt event, or any combination of these effects, would be necessary to generate this condition.

The most likely potential consequence of the reactivation of this landslide deposit would be the creation of unstable ground that would pose a navigational hazard for hikers on the deposits themselves. The integrity of archeological sites on the deposits would be threatened should movement continue for any extended period of time. The remote possibility also exists for the landslide deposits to move into Capulin Canyon and dam Capulin Creek, although there is no evidence to indicate that this occurred in the past. Should this occur, catastrophic failure of the dammed material and the resultant flooding could result in destruction of downstream archeological sites, as well as the loss of human life.

The likelihood of reactivation of these deposits appears to be so slight at this time that no restrictions of access to Capulin Canyon due to this threat appears to be necessary.
Most importantly, a general awareness of the state of the landslide deposits by those working in the canyon can be extremely useful in evaluating their continued stability:

- The steep section of the landslide toe in Capulin Canyon (between points B and D on Figure 1) should be monitored for signs of steepening or erosion by the creek.

- Formation of cracks and shears within the deposits, particularly in the areas of stepped topography on the lateral margins of the primary block could indicate reactivation.

- The presence of new seeps or springs, or increased flow in existing seeps or springs along the toe of the landslide deposits in Capulin Creek or at the heads of channels on the deposits, could indicate increased groundwater flow through the deposits in response to increased infiltration into the burned area.

- The development of areas with numerous tilted trees should be noted.

Should these conditions arise, access restrictions should be considered for Capulin Creek downstream from the landslide deposits.

And finally, in light of the predictions of higher than average snow and rainfall accumulations in the southwest in response to the 1997-98 El Nino event, we recommend continuing monitoring of soil-moisture conditions on the Boundary Peak landslide, as well as a repeat GPS survey of the established monument array. 
Allen, C.D., 1989, Changes in the landscape of the Jemez Mountains, New Mexico: Ph.D. dissertation, University of California, Berkeley.

Brooks, R.H., and Corey, A.T., 1966, Properties of porus media affecting fluid flow: Journal of Irrigation and Drainage Division, American Society of Civil Engineers, v. 92, p. 61-88.

Burdine, N.T., 1953, relative permeability calculations for pore-size distribution data: Petroleum Transactions, American Institute of Mining Metallurgy Engineering, v. 198 , p. 71-77.

Campbell, R.E., Baker, M.B., Jr., Ffolliott, P.F., Larson, F.R., and Avery, C.C., 1977, Wildfire effects on a Ponderosa pine ecosystem: USDA Forest Service Research Paper RM-191, Rocky Mountain Forests and Range Experiment Station, Fort Collins, Colo., 12 p.

Cannon, S.H., 1997, Evaluation of the potential for debris and hyperconcentrated slows in Capulin Canyon as a result of the 1996 Dome fire, Bandelier National Monument, New Mexico: U.S. Geological Survey Open-File report 97-136, 20 p.

Cannon, S.H. and Ellis, W.L., 1997, Preliminary evaluation of the landslide potential in Capulin Canyon following the Dome fire, Bandelier National Monument, New Mexico: U.S. Geological Survey Open-File Report 97-141, 15 p.

Craig, R.F., 1987, Soil Mechanics, Fourth Edition: Van Nostrand Renhold (UK) Co. Ltd, $410 \mathrm{p}$.

DeBano, L.F., and Letey, J., 1969, Waterrepellent soils: University of California, Riverside, May 6-60, 1968, Proceedings, 354. p.

Eldredge, E.P., Shock, C.C., and Steiber, T.D., 1993, Calibration of granular matrix sensors for irrigation management: Agronomy Journal, v. 85. no.6, p. 12281232.
Fleming, R.W., and Johnson, A.M., 1989, Structures associated with strike-slip faults that bound landslide elements:

Engineering Geology, v. 27, p. 39-114.

Goff, Fraser, Gardner, J.N., and Valentine, Greg, 1990, Geology of St. Peter's Dome Area, Jemez Mountains, New Mexico: New Mexico Bureau of Mines and Mineral Resources, Geologic Map 69.

Kalendovsky, M.A., and Cannon, S.H., 1997, Fire-induced water-repellent soils: an annotated bibliography: U.S. Geological Survey Open-File Report 97-720, 41 p.

Phipps, R.L., 1974, The soil creep-curved tree fallacy: Journal of Research of U.S. Geological Survey, v. 2., no. 3, p. 371-377.

Reneau, S.L., Gardner, J.N., and Forman, S.L., 1996, New evidence for the age of the youngest eruptions in the Valles caldera, New Mexico: Geology, v. 24, no. 1, p.7-10.

Shock, C.C., and Barnum, J.M., 1992, Improving irrigation management of potatoes with granular matrix sensors: Proceedings of the 25th Oregon Potato Conference.

Stieber, T.D., and Shock, C.C., 1995, Placement of soil moisture sensors in sprinkler irrigated potatoes: American Potato Journal, v. 28, p. 533-543.

vanGenuchten, M.T., 1980, A closed-form equation for predicting the hydraulic conductivity of unsaturated soils: Soil Science Society of America Journal, v. 44, p. 892-989.

Zwolinski, M.J., 1971, Effects of fire on water infiltration rates in a ponderosa pine stand, in Hydrology and Water Resources in Arizona and the Southwest: Arizona Section of the American Water Resources Association and the Hydrology Section Arizona Academy of Sciences, Tempe, Arizona, April 22-23, 1971, Proceedings, v. 1, p. 107-112. 